\title{
Survey of drawing and art activities of preschoolers: Attitudes and experiences of parents
}

\author{
Sigita Lesinskiene ${ }^{1 *}$, Auge Lesinskaite ${ }^{2}$, Rokas Sambaras ${ }^{2}$ and Virginija Karaliene ${ }^{3}$ \\ ${ }^{1}$ Clinic of Psychiatry, Faculty of Medicine, Institute of Clinical Medicine, Vilnius University Lithuania \\ ${ }^{2}$ Faculty of Medicine, Vilnius University, Lithuania \\ ${ }^{3}$ Karoliniskiu Polyclinic, Karoliniskiu Mental Health Center, Lithuania
}

\begin{abstract}
Drawing is an especially important activity for preschool children who do not yet possess verbal skills to express their feelings. The various aspects of children drawing can be widely implemented as diagnostic and therapeutic measures in home environment and many different settings, especially pediatric, developmental, and dental services, starting school, classroom observations. Objective of the study was to review the aspects of drawing in preschoolers and to investigate the attitudes of their parents considering their own artistic experiences and visual arts education. A pilot survey was conducted using a 22 -item questionnaire designed for this specific purpose. Preschooler parents were interviewed in 6 public kindergartens in Lithuania. The questionnaire consisted of general questions about the parents and children as well as specific questions regarding the various aspects of drawing materials, time, type of visual art activities, parent attitudes and their own experiences and engagement in visual arts. The survey has determined that the majority of children draw, model, and color books, and that the parents have noted the various beneficial aspects of said activities. Girls participated in visual art activities at home significantly more than boys. Parents who participated in specialized art activities during childhood had children who were engaged in art activities (both drawing and modeling) significantly more and who were less engaged in book coloring at home. The current data can be used for longitudinal and cross-cultural comparisons.
\end{abstract}

\section{Introduction}

Children all around the world enjoy drawing. This is due to their inner creativity finding its way through visual cues as well as motor, cognitive, and emotional development. Drawing is an especially important activity for children who do not yet possess verbal skills to express their feelings. It is through drawing that they reveal both joyful and worrisome issues as valuable and important aspects of their lives.

The means and methods that children utilize for drawing may differ from country to country and the dynamic may change, so further research is necessary. Another aspect that lacks research is the opinions of the parents, the trends dominating in societies, and the changing habits and approaches to parenting. We are of the opinion that when it comes to children's drawings, it is important to consider the view of the parents towards the drawings of their children and of their personal connection to art, as well as the conditions that the parents form for children to draw, color, and craft at home.

Research suggests that with age more complex and symbolic representational strategies develop and reference points become more differentiated by gender [1]. Drawing can be described as an meaning-making activity that takes place in certain sociocultural contexts to find evidence for its communicative potentials as well as the relationship between thought and drawing in early childhood [2]. Children's drawing behavior develops together with their cognitive skills (e.g. thinking, problem-solving, remembering) and emotional development. It requires the ability to grasp and position a drawing tool and transfer thoughts into intentional hand movements [3]. The study of preschoolers has determined that as children become more skilled, detailed and planned in their drawing, their level of cognitive development rises [4].
Every child's drawings are unique, and their contents and the ways of drawing and colouring them reflict important emotions, thoughts and fears as well as the possibilities to regulate emotions, perceive and draw human figure, as well as other important elements [5-8]. The various aspects of children drawing can be widely implemented as diagnostic and therapeutic measures in many different settings, especially pediatric, developmental, and dental services, starting school, classroom observations, and other [9-18].

Insightful and relevant research data regarding the relationship between a children's narrative and their drawing process, concentrating on listening to the children as they work may provide a deeper understanding of their thinking and developing sentience [19]. There is also an ongoing research discussion on issues concerning the analysis of visual data-in particular, how the imaginative input of the child was analyzed and how that process required additional written descriptions as a secondary data source [20].

We believe that a broader and more thorough analysis would be beneficial to specialists and parents alike so as to foster greater understanding and a perceptive attitude towards their children's creativity, imagination, and drawing. The variety of measures and

Correspondence to: Sigita Lesinskiene, Clinic of Psychiatry, Faculty of Medicine, Institute of Clinical Medicine, Vilnius University, Lithuania, Tel: +370686 17550; E-mail: sigita.lesinskiene@mf.vu.lt

Key words: Drawing, Materials, Modeling, Coloring, Preschool children, Parents engagement in visual arts

Received: March 10, 2018; Accepted: March 23, 2018; Published: March 26, 2018 
possibilities for drawing and for becoming engaged in artistic activities are changing in many societies. At the moment, there is little research done on the issue, but parent experience as well as their personal connections and participation in visual art activities relating to their children's drawing patterns is a new and exciting area of study.

\section{Objective}

To review the aspects of drawing in preschoolers and to investigate the attitudes of their parents considering their own artistic experiences and visual arts education.

\section{Method}

A pilot survey was conducted using a 22-item questionnaire designed by the first author for this specific purpose. Preschooler parents were interviewed in 6 public kindergartens in Lithuania. The questionnaire consisted of general questions about the parents and children as well as specific questions regarding the various aspects of drawing materials, time, type of visual art activities, parent attitudes and their own experiences and engagement in visual arts. Data was analyzed using Microsoft Excel 2013 and SPSS 21. The frequencies of each item were compared among groups using the chi-squared test. A $\mathrm{p}<0.05$ value was considered statistically significant.

\section{Results}

361 parents have completed the survey. 272 (75.3\%) were mothers and $89(24.7 \%)$ were fathers. The average age of mothers was $34.2 \pm$ 5.06 , and the average age of fathers was $36.5 \pm 5.35$. Parent education level: university graduates (67\%), undergraduate vocational bachelors (20\%), high school graduates (12\%), other (1\%). Parent marital status: married (80.6\%), divorced (8.3\%), single (6.7\%), widow/widower (1.1\%), other $(3.3 \%)$. The average number of children being raised in families was $1.9 \pm 0.8$.

The following are statistics based on answers that parents provided regarding their children: $195(54.5 \%$, average age $5.1 \pm 1.1)$ were girls, $163(45.5 \%$, average age $5.0 \pm 1.1)$ were boys, and 3 did not specify their children's gender. Interview data has shown that 339 (93.9\%) children were drawing at home, of which $144(83.3 \%)$ were boys and
$192(98.5 \%)$ were girls $(\mathrm{p}=0.00) .324(89.8 \%)$ parents have noted that their child likes drawing.

Drawing materials that the parents have listed as most used by their children at home: coloring pencils $(289,80.1 \%)$, watercolor (173, $47.9 \%)$, color chalk $(137,38.0 \%)$, drawing pencil $(115,31.9 \%)$, felttip pens $(105,29.1 \%) .245$ (67.9\%) children were modeling at home, of which $75.9 \%$ were girls and $58.3 \%$ were boys $(\mathrm{p}<0.00)$. Modeling materials: plasticine (53\%), modeling clay (36\%), clay (6\%), putty $(3 \%)$, kinetic sand (2\%).

$312(86.4 \%)$ of children colored books, of which $93.8 \%$ were girls and $77.3 \%$ were boys $(\mathrm{p}<0,00)$. Table 1 demonstrates how frequently children drew, modeled, and colored at home.

$259(71.8 \%)$ parents noted that they liked to draw and $213(59.0 \%)$ noted that they liked to model during their childhood. 79 (21.9\%) parents were attending specialized art programs or art schools during their childhood. Figures 1 and 2 illustrate the findings of this study, i.e. that the children of parents who used to draw and model during their childhood were drawing and modeling significantly more $(\mathrm{p}<0.00)$.

The parents were categorized into 4 groups: parents who did not participate in visual art activities during childhood and who do not participate in visual art activities today; parents who participated in visual art activities during childhood and continue to participate in visual art activities today; parents who participated in visual art activities during childhood, but do not participate in visual art activities today; and parents who did not participate in visual art activities during childhood, but who participate in visual art activities today.

Having compared all of the groups among each other based on how their children drew, modeled and colored, we have determined statistically relevant differences among the groups based on drawing ( $p=0.004)$ and book coloring $(\mathrm{p}=0.002)$. Table 2 demonstrates all of the compared data.

Having compared the 4 groups among each other based on how the children of the parents drew, modeled, and colored, we have determined a statistically significant difference: parents who have participated in visual art activities during childhood and who currently
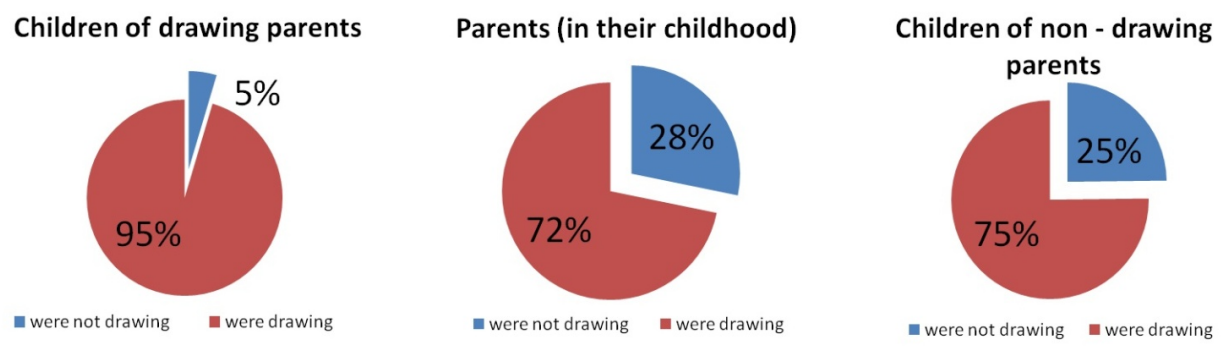

Figure 1. Engagement in drawing among subgroups of parents.
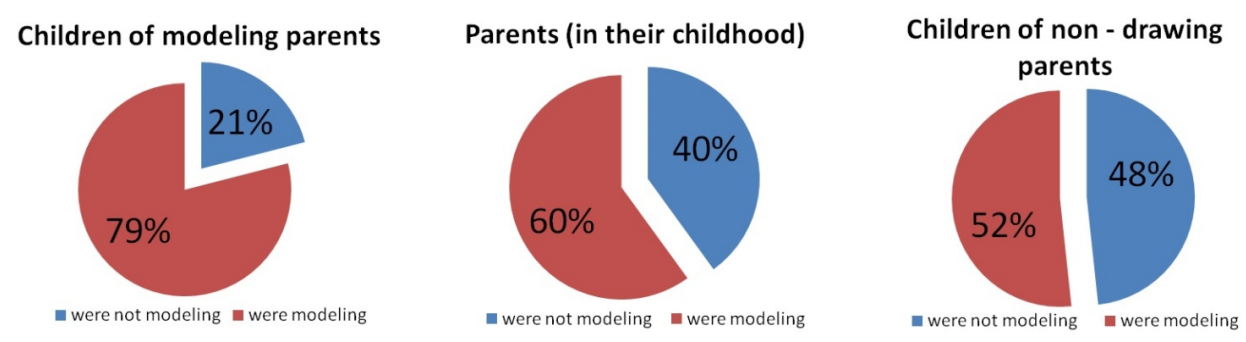

Figure 2. Engagement in modeling among subgroups of parents. 
Table 1. Parents responses about frequency of their child art activities.

\begin{tabular}{|c|c|c|c|}
\hline & Drawing & Modeling & Coloring \\
\hline Every day & $40 \%$ & $3 \%$ & $17 \%$ \\
\hline More than 1 time per week & $44 \%$ & $32 \%$ & $60 \%$ \\
\hline Less than 1 time per week & $16 \%$ & $65 \%$ & $23 \%$ \\
\hline
\end{tabular}

Table 2. The relationship between children's engagement in art activities and parent childhood and their current experiences with visual arts.

\begin{tabular}{|c|c|c|c|c|}
\hline & $\begin{array}{c}\text { Parents currently not } \\
\text { involved in visual art } \\
\text { activities } \\
\mathbf{2 4 3 ( 6 7 . 3 \% )}\end{array}$ & $\begin{array}{c}\text { Parents who studied at art } \\
\text { school during childhood } \\
\text { and who are currently } \\
\text { involved in visual art } \\
\text { activities }\end{array}$ & $\begin{array}{c}\text { Parents who studied at art } \\
\text { school during childhood, } \\
\text { but who are currently } \\
\text { not involved in visual art } \\
\text { activities } \\
\mathbf{4 2 ( 1 1 . 6 \% )}\end{array}$ & $\begin{array}{c}\text { Parents currently involved } \\
\text { in visual art activities, but } \\
\text { who have not studied at an } \\
\text { art school during childhood } \\
\mathbf{3 9}(\mathbf{1 0 . 8 \% )}\end{array}$ \\
\hline Children drawing & $213(87.7 \%)$ & $36(97.3 \%)$ & $38(90.5 \%)$ & $37(94.9 \%)$ \\
\hline Children modeling & $150(61.7 \%)$ & $28(75.7 \%)$ & $35(83.3 \%)$ & $32(82.1 \%)$ \\
\hline Children coloring & $219(90.1 \%)$ & $25(67.6 \%)$ & $36(85.7 \%)$ & \\
\hline
\end{tabular}

participate in said activities had children who were less inclined to color books $(25,67.6 \%)$, as opposed to the children of parents who have not participated in visual arts activities and who do not currently participate in said activities $(219,90.1 \%, \mathrm{p}<0.001)$.

Moreover, we have also determined another statistically significant difference in how the children of parents who participated in visual arts activities during childhood $(35,83.3 \%)$ or who are currently participating in visual arts activities $(32,82.1 \%)$ were more inclined to model than children of parents who did not participate in visual arts activities and who do not currently participate in said activities (150, $61.7 \%, \mathrm{p}=0.007, \mathrm{p}=0.014$ ).

The comparison of other groups to each other provided no statistically relevant differences.

95.9\% of parents have noticed that drawing is beneficial to their children's development. Figure 3 specifies the drawing benefits that the parents have provided. The remaining 5 parents said that drawing is unnecessary and a needless activity, noting that some children may not like drawing, while activities such as sports and singing may be more favorable and educative to them.

\section{Discussion}

The current pilot research has determined that the majority of children draw, model, and color books, and that the parents have noted the various beneficial aspects of said activities. Girls participated in visual art activities at home significantly more than boys. More parents who have studied visual art during childhood noted that their children are more inclined to model. The children of parents who currently draw and create works of art were also more inclined to draw and model. Children of parents who have studied visual art during childhood and who currently participate in artistic activities colored books less and chose to draw ships more often. Data obtained in this study can be used for cross-cultural comparisons, in both cross-sectional studies and when researching periodic changes in action.

Drawing is a widely accepted activity for preschoolers. However, parents and teachers adopt a variety of views regarding the nature and importance of this activity [2]. For various reasons, the interest of parents and child specialists in the importance of child drawing and its benefits to personal development may increase (whether greatly or insignificantly), but it may also be the case that they will not consider free drawing as important as linguistic development and learning to write and read. The results of our study have determined that children participate in free drawing at home more often than they color books

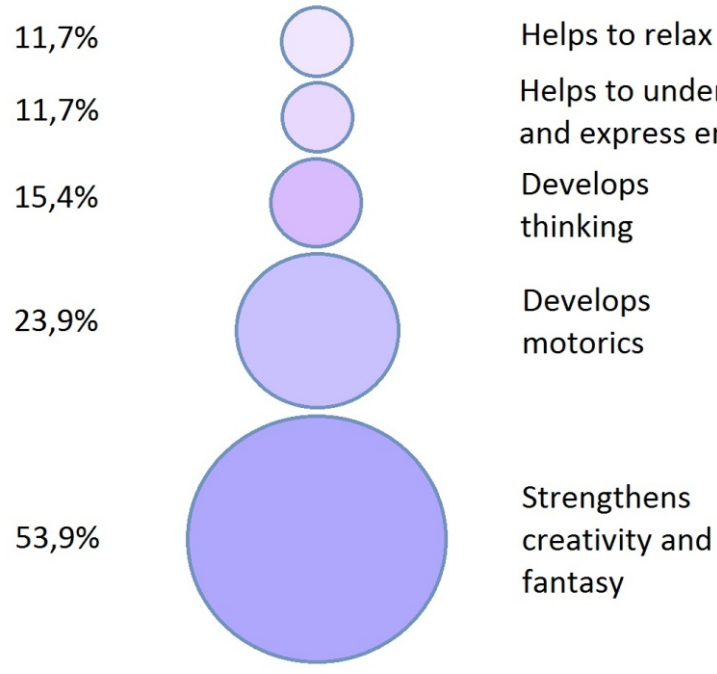

Figure 3. Benefits of drawing as noted by parents.

(93.9\% and $86.4 \%$ respectively). The children of parents who have experience in visual art activities took part in book coloring the least. It would be interesting to observe the change of this relationship in action. Free drawing and coloring of pre-prepared shapes develops different areas and functions of a child's personal development.

The cultural components of drawing allow one to consider it a symbolic form of cultural communication when focus on the way the children are given the opportunity to draw, their spontaneous uptake, and on the different modalities through which they discover relationships between drawings and the objects they represent [21]. Drawing materials, shared child-adult attention, dyadic asymmetrical relationships, and reciprocal involvements are found to be present in all contexts [21]. The drawing process itself, how the child creates the drawing, what the child starts with, and what the child says or what stories he or she tells are also very important. We have not studied these aspects. Further research may benefit form asking the parents, whether they observe their children while they draw and whether they talk to them during the drawing process or having finished the drawing. If there are several children growing up in the family, it is important to observe their conversations and interaction with each other.

Young children have many motivators for drawing, regardless of purpose and context, and this needs recognition on both a political and practical level [22]. There may exist mixed messages in curricular documents regarding the role and value of drawing in early education. 
The documents state that children should be encouraged to explore their ideas, feelings, and experiences through a range of means, including drawing, but drawing as a form of communication is predominantly seen as a pre-writing skill [22]. Greater opportunities for implementing drawing and modeling should also be created through the medical and educational regulations and find relevant place in documentary regulations of the countries.

As time passes, drawing habits and materials change in many countries and cultures. It is also an interesting element within the field worthy of a separate investigation. It is important to study and observe what trends form in action: are the children allowed to draw freely, are there conditions for them to foster and express their imagination, or are they more encouraged to color books or pre-prepared shapes?

The results of our study show that there are more children who participate in free drawing rather than book coloring, but both activities are common. Free drawing and shape coloring are necessities, fostering various aspects of a child's complex development system. It would be interesting to determine how the dominance of these activities differs form culture to culture by observing the trends in action.

\section{Conclusion}

Most preschoolers were drawing, modeling, and coloring books at home, with girls doing it significantly more often than boys. Parents who participated in specialized art activities during childhood had children who were engaged in art activities (both drawing and modeling) significantly more and who were less engaged in book coloring at home. $95,9 \%$ of parents said that drawing is beneficial to the development of the child by indicating various aspects. The current data can be used for longitudinal and cross-cultural comparisons.

\section{References}

1. Cherney ID, Seiwert CS, Dickey TM, Flichtbeil JD (2006) Children's drawings: a mirror to their minds. Educational Psychology 26: 127-142.

2. Papandreou M (2014) Communicating and Thinking through Drawing Activity in Early Childhood. Journal of Research in Childhood Education 28: 85-100.

3. Kortesluoma RL, Punamaki RL, Nikkonen M (2008) Hospitalized children drawing their pain: the contents and cognitive and emotional characteristics of pain drawings. $J$ Child Health Care 12: 284-300. [Crossref].

4. Chappell PA, Steitz JA (1993) Young Children's Human Figure Drawings and Cognitive Development. Percept Mot Skills 76: 611-617. [Crossref].
5. Naglieri JA, McNeish TJ, Bardos AN (1991) DAP: SPED. Draw-a-Person: Screening Procedure for Emotional Disturbance. Examiner's Manual. Austin, TX: Pro-Ed.

6. Drake JE, Winner E (2013) How children use drawing to regulate their emotions. Cogn Emot 27: 512-520. [Crossref]

7. Cox MV, Moore R (1994) Children's depictions of different views of the human figure, Educational Psychology 14: 427-436.

8. Cox MV, Ralph ML (1996) Young Children's Ability to Adapt their Drawings of the Human Figure. Educational Psychology 16: 245-255.

9. Malchiodi CA (2001) Using Drawing as Intervention with Traumatized Children Trauma and Loss: Research and Interventions 1: 21-28.

10. Stein, MT (2001) The Use of Family Drawings by Children in Pediatric Practice. Journal of Developmental and Behavioral Pediatrics 22: S49-S54.

11. Lesinskienė S (2002) Children with Asperger syndrome: specific aspects of their drawings. International Journal of Circumpolar Health 61: 90-96.

12. Lesinskienè S, Mickevičiūtè D (2005) Emotional state and drawings of children suffering from oncohematological diseases. Pediatrics (Journal in Lithuanian, ISSN 1648-4630), 14: 54-61.

13. Matsumori N (2005) Use of Drawing Technique in Nursing assessment. Journal for Specialists in Pediatric Nursing 10: 191-195.

14. Lesinskienė S, Dapkute A, Balod A (2005) Analysis of paintings made by children with linguistic disorders. In Arts - therapies - communication Vol. III, Kossolapow L., Scoble S., Waller D., (eds.), LIT Verlag Munster, Transaction Publishers pp. 121-131.

15. Aminabadi NA, Ghoreishizadeh A, Ghoreishizadeh M, Oskouei SG (2011) Can drawing be considered a projective measure for children's distress in paediatric dentistry? Int $J$ Paediatr Dent 21: 1-12. [Crossref]

16. Lesinskienė S, Furmanskytė R, Albužytė I (2013) Investigation of children's attitude towards doctors. Pediatrics (Journal in Lithuanian, ISSN 1648-4630) 1: 76-80.

17. Einarsdottir J, Dockett S, Perry B (2009) Making meaning: children's perspectives expressed through drawings. Early Child Development and Care 179: 232.

18. Early DM, Iruka IU, Ritchie S, Barbarin OA, Winn DM, et al. (2010) Early Childhood Research Quarterly 25: 177-193.

19. Coates E, Coates A (2006) Young children talking and drawing. International Journal of Early Years Education 14: 221-241.

20. Bland D (2012) Analysing children's drawings: applied imagination. International Journal of Research \& Method in Education 35: 235-242.

21. Pinto G, Gamannossi BA, Cameron CA (2011) From scribbles to meanings: social interaction in different cultures and the emergence of young children's early drawing. Early child Development and Care: 181: 425-444.

22. Hall E (2009) Mixed messages: the role and value of drawing in early education. International Journal of Early Years Education 17: 179-190.

Copyright: (C2018 Lesinskiene S. This is an open-access article distributed under the terms of the Creative Commons Attribution License, which permits unrestricted use, distribution, and reproduction in any medium, provided the original author and source are credited. 